\title{
Present Situation and Application of Urban Underground Parking Lots
}

\author{
Tan Zhongsheng, Wang Mengshu, Wang Yonghong, Chen Xueying
}

School of Civil Engineering, Beijing Jiaotong University, Beijing 100044, China

\begin{abstract}
Parking problems have become increasingly prominent, seriously affecting the urban environment and traffic order. Currently, better utilization and transformation of lots as well as constructing new urban underground parking lots are the most effective methods of solving parking problems. This study analyzes existing problems in construction management and the planning, design, and construction of underground parking lots through a case investigation of domestic and foreign cities. To address these problems, recommendations for planning and design, an operating model, and investment and financing modes are proposed to guide the scientific and effective development of underground parking lots and solve urban traffic congestion.
\end{abstract}

Keywords: underground parking lots; parking policy; construction management; planning and design; construction

\section{Introduction}

Along with rapid economic development in China, people's living standards are gradually increasing, and the number of private cars is increasing daily. While enjoying the convenience brought by cars, people must also face the resultant traffic jams, parking difficulties, environmental pollution, and other social issues. Currently, the number of motor vehicles in first-tier and second-tier cities continues to increase, and the demand for parking is constantly expanding. Constructing infrastructure for parking lots in major cities lags behind the development of cars, and, consequently, the demand for parking management cannot keep up. As such, "disorderly parking” has intensified, seriously affecting the urban environment and traffic order. It has become urgent need to solve the problem of parking in urban areas, especially in city centers.

Underground parking can take full advantage of underground space, which provides a practical solution to the current parking problems. However, because of problems pertaining to parking and collecting cars, the high cost of parking, and lack of combination between static traffic and dynamic traffic, many underground parking lots are empty in some areas at specific times. Many key issues must be solved to promote underground parking lots in China. Therefore, this paper studies the necessity and urgency of the construction of underground parking lots, as well the planning and design, operation, and investment and financing thereof to contribute toward solving problems pertaining to urban traffic congestion and the planning and construction of urban underground parking lots.

\section{Necessity and urgency of constructing underground parking}

\subsection{Status of parking and problems in China's cities}

An investigation and analysis of the city parking system in China revealed the following five major problems.

\subsubsection{Large gaps between parking space supply and demand}

As China's social economy continues to develop, the number of those owning cars is rapidly growing. As shown in Fig. 1, as of the end of March 2017, car ownership in the country totaled

Received date: December 1, 2017; Revised date: December 20, 2017

Corresponding author: Tan Zhongsheng, School of Civil Engineering, Beijing Jiaotong University, Professor. Major research fields include new theory of underground engineering design and construction technique. E-mail: zstan@vip.sina.com

Funding program: CAE Advisory Project “Development Strategy for Urban Underground Space Planning in China” (2015-XZ-16)

Chinese version: Strategic Study of CAE 2017, 19 (6): 100-110

Cited item: Tan Zhongsheng et al. Present Situation and Application of Urban Underground Parking Lots. Strategic Study of CAE, https://doi.org/10.15302/ J-SSCAE-2017.06.015 
200 million, and exceeded 1 million in 49 cities across the country. Furthermore, 19 cities have more than 2 million vehicles, of which 3 million are registered and filed in six cities, namely Beijing, Chengdu, Chongqing, Shanghai, Suzhou, and Shenzhen. The average annual growth rate of car ownership in some cities exceeds $20 \%$.

In recent years, the number of parking facilities has steadily increased; however, there is still a shortage of parking space compared to the rapid expansion of parking demand [1]. For example, by March 2017, the number of vehicles in Beijing totaled 5.54 million, while there were only 1.9614 million parking places, about one third of the total vehicle ownership (Fig. 2). According to the experiences of domestic and foreign cities, each car in the city should have $1.2-1.3$ parking spaces. According to conservative estimates of a ratio of $1: 1$ cars and parking spaces, the gap between the supply of and demand for parking spaces in Beijing is 3.58 million. According to the data released by the National Development and Reform Commission, the average proportion of cars and parking places in China's big cities is about $1: 0.8$, and around $1: 0.5$ in small and medium-sized cities [2]. As a standard, a gap is evident between the supply of and demand for parking spaces in most cities in China, substantiating the urgency of constructing underground parking lots.

2.1.2 Unreasonable parking space and a serious shortage of parking facilities

In traffic engineering, three types of parking lots are identified: the parking lots of public buildings, outside parking lots, and roadside parking lots. A ratio of $6: 2: 2$ of the three types indicates a reasonable parking structure [3], although this ratio in many cities in China is $1: 5: 4$. Thus, the parking lots of public buildings, which can play a leading role, theoretically only play a supplementary role.

\subsubsection{Side parking}

According to the survey and statistics, side parking is common in many cities in China. Side parking occupies sidewalks and non-motorized lanes, affecting the capacity of the road,

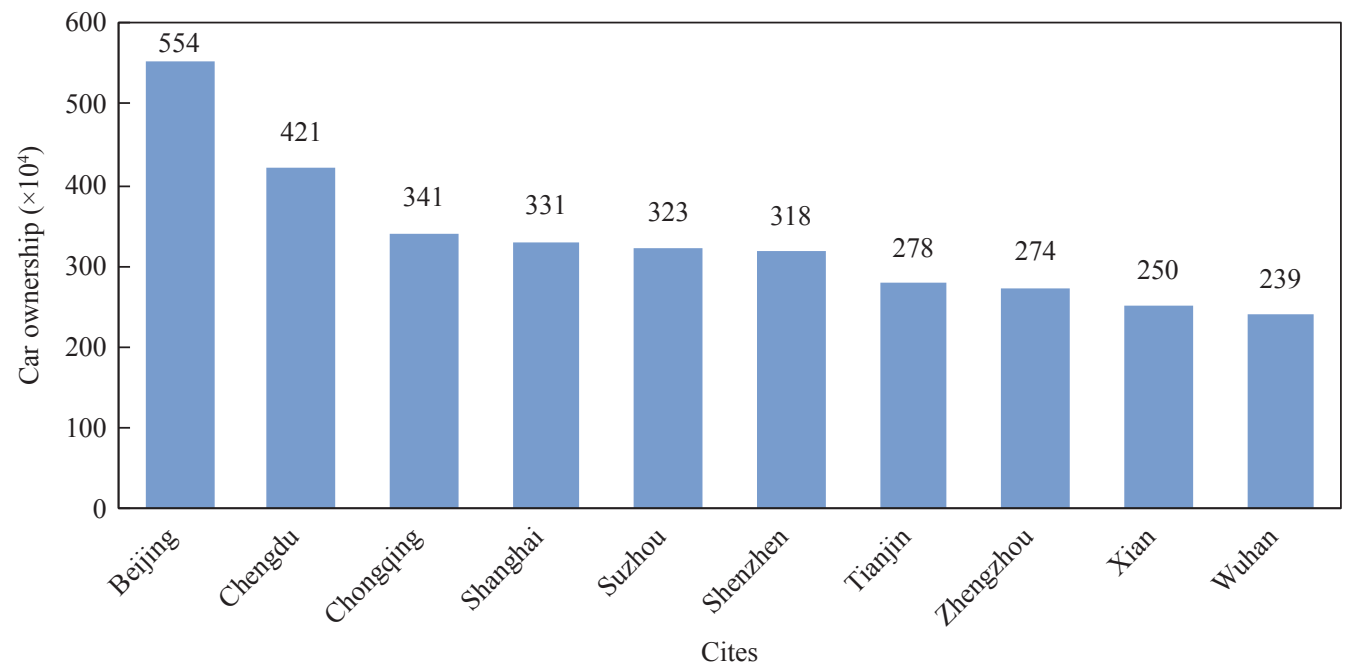

Fig. 1. Car ownership in major cities in China in 2016.

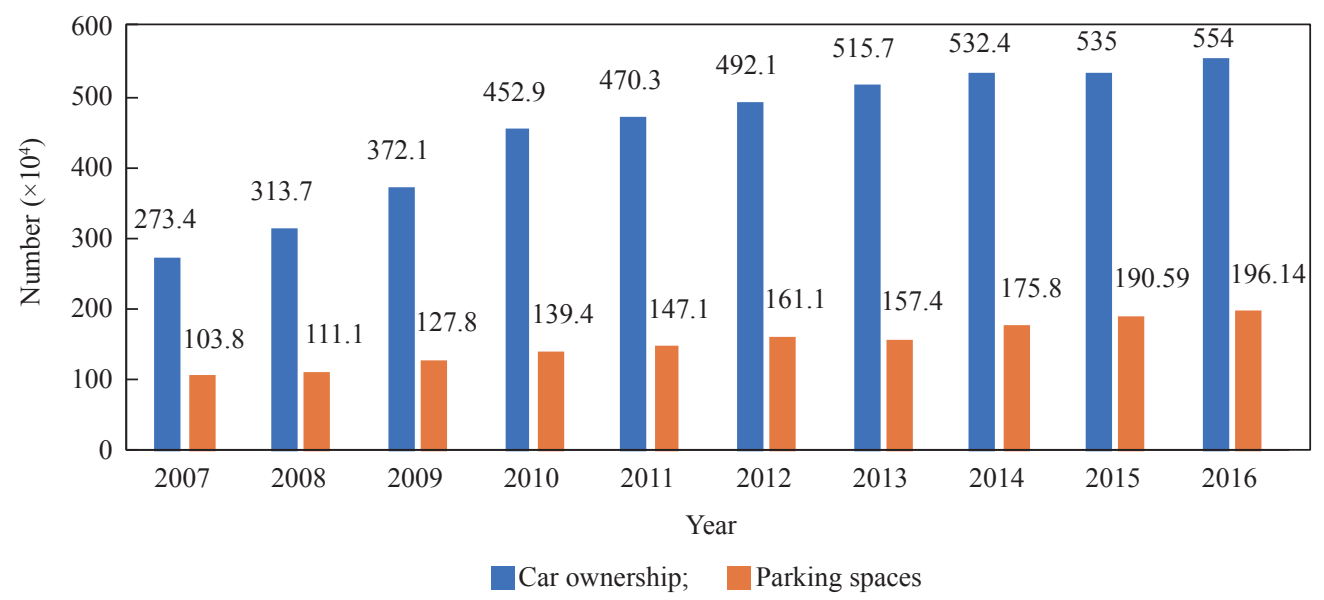

Fig. 2. Car ownership and parking spaces in Beijing from 2007-2016. 
which can easily lead to many problems such as traffic disorder and traffic accidents [1].

2.1.4 Unreasonable planning and design of existing parking lots

The unbalanced layout of and demand for public parking facilities, uneven distribution of parking facilities, and inaccurate forecasting of parking demand means that some parking lots face the problems of low utilization and poor operating conditions, despite severely limited parking spaces in China. In addition, the form of the planned and designed parking lots is monotonous, and most are ground parking lots. Mechanical parking lots with high space utilization and high efficiency are used less often [1].

\subsubsection{Residents are not strongly law abiding}

Illegal parking by residents who do not abide by the law is also one reason for parking problems [4]. Because of the shortage of parking resources, many people park directly on the roadside, which affects traffic and negatively impacts the urban environment. However, the penalty for illegal parking in China is extremely low, which condones and intensifies parking difficulties.

\subsection{Analysis of the development of parking policy}

In view of the parking problems, relevant policies for parking lots have been launched at all levels of the country, aiming to guide and coordinate various aspects including funding, planning, and construction to promote the development of parking lots.

In 2015, the National Development and Reform Commission, Ministry of Finance, Ministry of Land and Resources, and four other ministries issued the Guiding Opinions on Strengthening the Construction of Urban Parking Facilities (hereinafter referred to as Opinions). It calls for fully mobilizing social capital, accelerating the construction of parking facilities, and effectively alleviating the shortage of parking space [5]. The 13th FiveYear Plan for Urban Underground Space Development and Utilization also proposed the development of underground parking requirements. At present, 18 cities nationwide have promulgated 31 laws and regulations relating to the construction of parking lots, including the aspects of land allocation and transfer, commercial facilities up to $50 \%$, tax relief, property tax exemption or land-use tax exemption, incentive subsidies, and charging the market regulation price.

Many cities have promulgated local regulations and policies that encourage the construction of public parking lots and guide private capital investment in these. However, the effect of promoting underground parking lots has not been significant for the following reasons. (1) Although local governments have promulgated various policies, these have not been implemented, as policy support is still in the text stage. (2) Although good conditions have been provided for building parking lots, support remains insufficient, making the cost of building underground parking lots too high. Thus, the expected return of investment cannot attract private capital. (3) Policies and regulations for parking lots are interlaced. In the process of engineering construction, many problems will emerge, such as multi-management and repeated auditing, which will affect the efficiency and enthusiasm of parking lot construction. Therefore, many key problems must be solved to popularize underground parking lots in China.

\section{Status of the development of parking lots abroad}

To solve the problem of irregular parking on the pavement and improve the capacity of roads and traffic conditions, many countries have adopted various policies and measures to strengthen the construction and management of parking lots. Currently, relatively perfect parking lot rules and an independent management system have been formed.

\subsection{Status of development of parking lots in Japan}

Because of its huge population, heavy traffic, and poor road conditions, Japan has been promoting vehicle parking construction and parking management through policy guidance, legal management, and technological innovation since the 1950s. Its main measures include the following three aspects.

3.1.1 Formulating relevant preferential policies to promote the construction of parking lots

(1) The main bodies overseeing parking lot construction are non-government institutions, who financially subsidize private and semi-private parking lots and encourage private capital investment in the construction thereof. (2) The country provides low-interest loans for the construction of parking lots through road development funds, special interest rate financing by banks, and NTT stock sales revenue. (3) Different tax relief regulations for taxes pertaining to the construction of parking lots [6], such as construction tax and enterprise income tax, have been introduced.

3.1.2 A law standardizes the construction and management of parking lots

As shown in Table 1, the laws and regulations pertaining to parking lot construction in Japan are effective, comprehensive, and detailed, covering the entire contents of parking lot construction and parking management. In addition, these were introduced earlier and revised to ensure the standardization and orderliness of parking lot construction and management [6].

3.1.3 Development of underground parking lots based on local conditions

(1) Japan advocates the promotion of three-dimensional me- 
Table 1. List of relevant laws and regulations for constructing a parking lot in Japan.

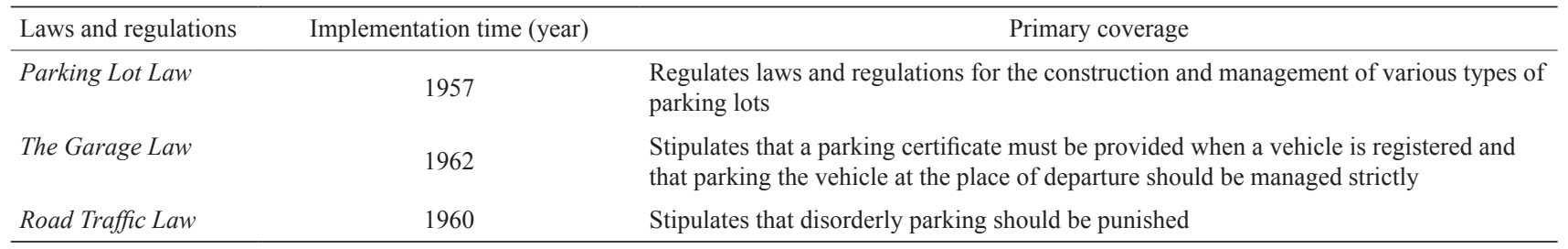

chanical garages, and was one of the earliest countries to adopt these. In the early 1960s, Japan developed and used a mechanical parking lot that maximized the use of space. By the end of 2014, the country housed 2.96 million mechanical parking spaces. (2) Furthermore, Japan actively advocates the principle of "small but decentralized," and encourages operators to make rational use of space to build small-scale parking lots. Some parking lots have only two or three parking spaces with flexible and convenient signage. (3) The country provides a comprehensive parking guide and parking guidance system to reduce unnecessary road exploration and roadside parking and to improve the efficiency of existing parking lots [7].

\subsection{Status of development of parking lots in Europe and the United States}

With the growth of traffic quantity, parking and related problems are becoming increasingly severe. Many European countries and the United States have adopted various parking policies to improve parking problems. These policies and measures involve urban planning and the rationalization of urban traffic structure [8]. The typical experience is as follows.

3.2.1 Increase parking lot capacity and reduce the gap between supply and demand

In the early stage of parking lot construction, European cities created conditions for short-term parking by placing temporary parking boards on streets. However, they later found that this method reduced the patency of the roads, and many countries canceled these measures [8]. In the middle and late stages of parking lot construction, major cities adapted to the growing parking demand by building three-dimensional and mechanized parking lots [9].

3.2.2 Perfect the laws and clarify the obligations of parking lot builders

Some cities in the United States require that enterprises within the service area of new parking lots and real estate owners bear part of the cost of parking construction to promote the construction of parking lots in the area [3].

\subsubsection{Strengthen the management of parking lots}

Britain has the most sophisticated parking management system in the world, and is one of the most successful countries in this regard worldwide. The Greater London Council (GLC), which is granted by the UK, has the mandatory right to curb traffic volume by controlling parking lots in the central part of the city where traffic is increasing to promote the use of public transport. The main approaches include the following. (1) Different parking time limits are set in different areas and the efficient operation of the parking spaces network is ensured by adopting a time-accumulated rate (charging higher fees for long-term parking users) and strictly enforcing the law [9]. (2) The country enhances the management of non-public parking lots by setting an upper limit on the size of the parking lots of public buildings, mobilizing the owners of private parking lots to open their spaces to the public, and taxing private parking lots to transform them into public parking lots.

3.2.4 Readjusting the urban traffic structure by implementing a new parking policy

In the mid-term of motorization, the development of parking facilities in urban centers has shifted from the construction stage to the improvement stage of intensive management. As a subsystem of the transportation system, parking lots are not only a problem of static traffic supply, but also an important means of "to treat dynamic traffic with static traffic." The parking policy is gradually being used as part of the urban planning and transportation policy to promote the adjustment of the urban traffic structure $[9,10]$. The main approaches are as follows: (1) limiting roadside parking through compensated use to improve road traffic capacity, (2) separating humans and cars by creating pedestrian streets and parking on the fringe area to control the traffic flow in the city center [9], and (3) building a park-and-ride (P\&R) parking lot to transfer vehicle traffic demand to public transport modes and adjusting urban traffic structure $[8,9]$.

\subsection{Status of development of parking lots in Singapore}

Singapore is a highly developed country. Its land area is small and population density is high. However, no serious parking problems are evident. The solution to the parking problem stems from the two aspects of supply and demand.

\subsubsection{The supply side}

(1) In densely populated urban areas, an advanced and intelligent parking network is used to develop a three-dimensional parking system to ensure that the capacity of public parking lots 
meets the demand. (2) The policy of "rent only and do not sell" is implemented in parking lots. There is no single fixed parking place in public residential buildings, private apartment buildings, and commercial service areas. Parking is based on a "first come, first park, and park at any time" basis to improve the utilization efficiency of parking lots [6].

\subsubsection{The demand side}

The government of Singapore does not encourage people to buy a car, as the annual cost of road maintenance totals tens of thousands yuan. This means that people can afford a car, but cannot afford to use it. Thus, the number of car owners is low, which controls the demand for parking from the source thereof.

\section{Construction management model for urban underground parking lots}

\subsection{Investment and financing model}

A large number of underground parking lots must be constructed; therefore, a large amount of funds is needed for construction. Furthermore, the construction of parking lots should be combined with the characteristics of the city and different parking construction projects should adopt different modes. Currently, there are three modes by which to construct underground parking lots in domestic and foreign cities, including government investment, joint investment between government and the private sector, and private investment under government control. The main financing modes for parking lots constructed jointly by the government and private sector or owned by the private sector include build-operate-transfer (BOT), build-transfer (BT), transfer-operate-transfer (TOT), transfer-build-transfer (TBT), and government and social capital cooperation.

In general, the public-private partnership (PPP) model is suitable for building non-profit parking facilities. It can attract public investors in accordance with the mode of public-private cooperation. The franchise period does not generally exceed 30 years, and the internal rate of return is usually less than $8 \%$. The government provides support if the actual income is lower than the target income. Other business parking lots can be constructed in a market-oriented way, and encourage investment in the construction and operation of parking lots through public-private partnerships using BOT or BT. The operation process for PPP projects regarding parking lots is illustrated in the PPP parking lot project in Luzhou city of China. As shown in Fig. 3, after determining the social capital procured, the project company completes a preliminary examination and approval procedures, as well as a survey and the design, construction, and other work required in the project. After completing project construction and acceptance thereof, the project company charges and manages the parking lot in accordance with the relevant regulations, and is responsible for its hygiene and maintenance, as well as for repairing the structure of the main components when needed. After 30 years of the project franchise, the project company transfers the project assets to project implementation agencies without compensation, and cancels its liquidation, after which the cooperation for the project is terminated.

\subsection{Ways to acquire construction land}

In the process of building an underground parking lot, obtaining construction land is a key issue. It is necessary to consider

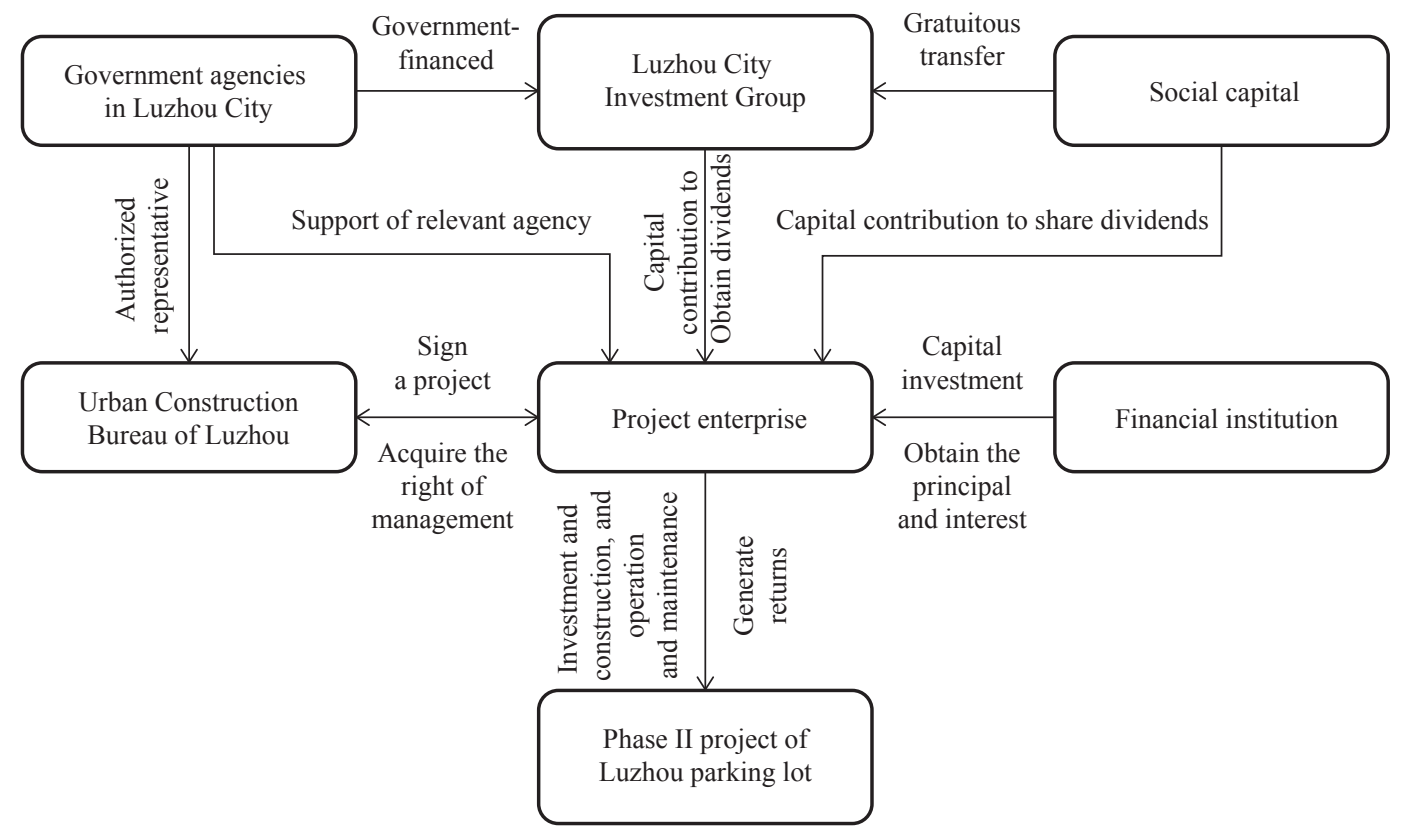

Fig. 3. PPP project investment and financing structure of Luzhou parking lot. 
the following situations. (1) The construction of a new project should match the underground parking lot. The land and property rights should be divided according to the nature of the new project. Furthermore, there is no additional land transfer fee. (2) The nature of the expanded underground parking lot is determined by the nature of the established project, and the land for the underground parking lot is obtained through a transfer, the same as for the main body. (3) The newly constructed public parking lots dominated by the government requires that local governments coordinate the purchase of land by local authorities, financial allocations, and investment by local state-owned companies. Newly constructed parking lots that employed the PPP model can attract social investors to participate based on "the government providing the land and the market the funds." (4) In general, land is acquired for the construction of underground parking lots through bidding, auctions, listings, and other means.

\subsection{Operations and management}

In terms of managing a parking lot, it is recommended to develop intelligent underground mechanical parking lots that consist of a unified code of parking space, vehicle geomagnetic sensors, intelligent vehicle terminals, Beidou high-precision ground enhanced positioning technology, wireless intelligent parking management terminals, a smart parking management system, automatic recognition system for vehicle licenses, user-oriented mobile apps, and other related high tech. With the establishment of intelligent underground mechanical parking lots, basic information, management information, and operational information on these lots (bits) can be summarized. Then, through the Internet, Internet of Things, big data, and other networking technologies, an intelligent parking management service platform can be established to be used to interconnect city-level parking lots and unify vehicle management, intelligent supervision and control, electronic payments, and car-related data sharing [5]. In the prevailing situation of the "Internet Plus" initiative, the promotion of intelligence and information management for parking lots uses Internet thinking to carry out management upgrades and change the profit model of the traditional parking industry, which can effectively increase the efficiency of the use of parking resources to relieve the problem of parking in cities.

In terms of parking management, it is recommended that a limited-time parking system be implemented. This entails charging for parking according to time, increasing the extent of punishment for parking violations, and limiting on-street parking. The implementation of these systems may result in some car owners switching to public transport, which will reduce the demand for parking lots accordingly. Large cities must prohibit parking on roads with heavy traffic. Compared to foreign countries, there is a large gap in terms of the implementation of regulations, strict punishment, and the refinement and fairness of terms. It is suggested that the government should escalate the parking issue to the legislative management level as soon as possible to ensure the rational use of parking resources.

\section{Classification and selection of underground parking lots}

There are many classifications for underground parking lots. According to different service groups, underground parking lots can be public or special types, or single-built and side-by-side according to the positional relationship with ground buildings. Based on different usage methods, they can be classified as ramp or mechanical types, or according to the size of the parking and requirements for fire prevention [7].

Among the types of urban underground parking lots, a mechanical underground garage demonstrates a high degree of automation and land use, and provides many advantages, such as a flexible layout and large parking density. Therefore, it provides a new direction for the development of urban parking facilities. There are different forms of underground mechanical parking lots. The main types are vertical lifting, circulating parking spaces, aisle-stacks, and lift-sliding [11].

\subsection{Vertical lifting underground mechanical parking lot}

The vertical lifting mechanical parking system generally has two vehicles on one level, and two cars are parked on each floor. The storage capacity of the parking lot is increased by the superposition of layers. This type of parking lot can generally be up to 20-25 floors. The common form is a tower-type three-dimensional parking lot constructed on the ground. It has a small footprint and demonstrates the highest land-use efficiency among all mechanical parking systems $[7,11]$.

The architectural plane of the cylindrical underground parking lot is circular. It reduces the number of floors by increasing the number of parking spaces on each floor of the system. General parking lots are reconstructed so that they can be better used in the underground space (Fig. 4). The cylindrical underground parking lot can be designed as a single circle or multi-circle combination. It mainly consists of a central circular area, surrounding circular areas, and the entrance. The central circular area is a transport channel, the surrounding circular areas provide parking space, which is fan-shaped, and the entrance of the parking lot is at the ground level, which can be freely selected according to needs regarding different angles. This type of parking lot requires an area of about $20 \mathrm{~m}$ in diameter, and has the advantages of a small footprint, large capacity, and short access time. Therefore, this type of parking lot is a practical solution to parking difficulties in old urban areas and urban centers.

\subsection{Circulating mechanical parking system}

The circulating underground mechanical parking system 


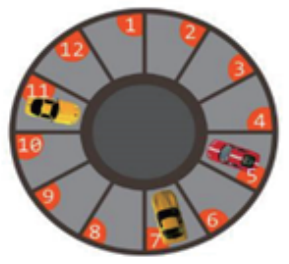

(a) Full circle type

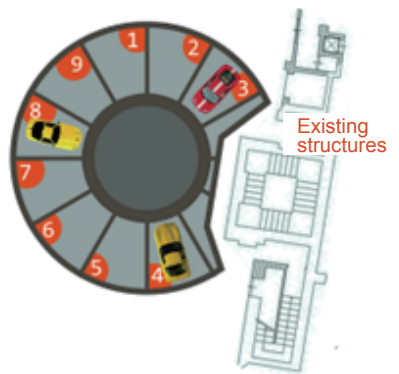

(b) Non-full circle type

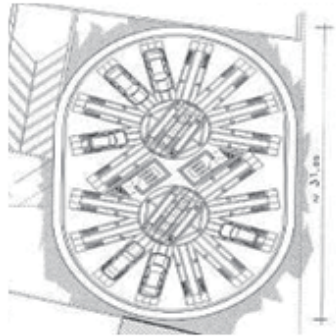

(c) Double circle type

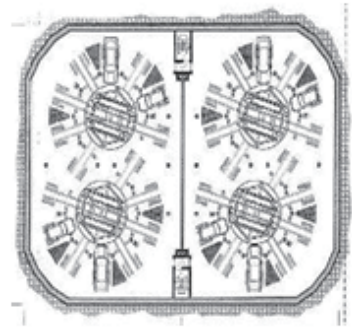

(d) Four-circle type

Fig. 4. Types of cylindrical underground parking.

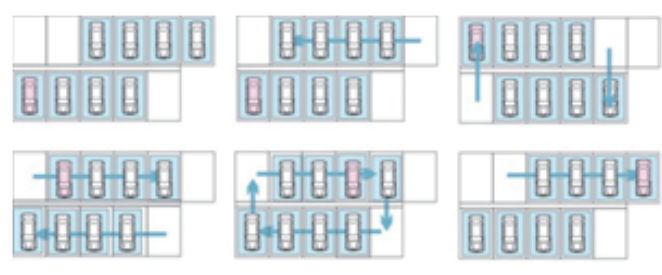

(a) Horizontal-cycle underground mechanical garage

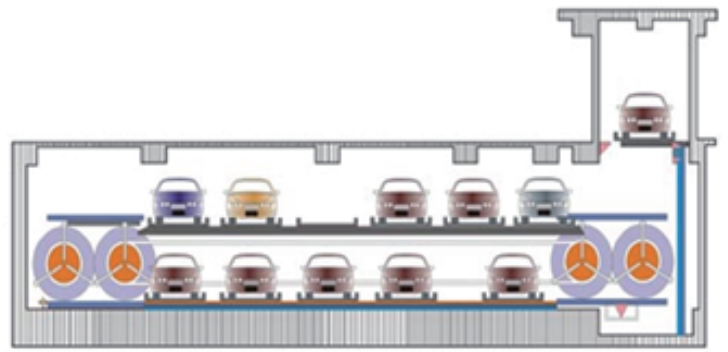

(b) Multi-layer cycle underground mechanical garage

Fig. 5. Types of circulating underground mechanical parking lots.

does not need to leave space for mechanical devices and lanes to access vehicles; thus, it demonstrates the best space utilization among all mechanical parking lot types [7], as shown in Fig. 5. Because of the different equipment used, this type can be categorized as a horizontal circulating mechanical parking system or multi-layer circulating mechanical parking system.

\subsection{Aisle-stack mechanical parking system}

This type of parking lot uses stacker cranes and other mechanical equipment to drive the vehicle to perform horizontal and vertical movements on dedicated passages and transport the vehicles to parking spaces, entrances, or exits. This type of parking lot needs space for the stacker cranes to run inside. Though there is lower utilization of space than in other circulating mechanical parking systems, its operating speed is faster [11]. The layout and sectional drawing of this type of parking lot are shown in Fig. 6.

\subsection{Lift-sliding mechanical parking system}

Parking spaces in this type of parking lot are organized in a multilayer and multi-seriate arrangement, and one empty space is set on each floor. When a vehicle needs to be collected, other vehicles move one space toward the empty one, creating a lifting channel below the parking space through which the vehicle can be accessed [7]. The structure of the lift-sliding mechanical parking system is simpler than the others and can take a modular design. Its advantages include high cost performance, strong adaptability, mature technology, and high reliability. It is the most used type of underground mechanical parking lot in China, and is shown in Fig. 7.

When selecting the type of underground mechanical parking lot, factors such as vehicle size, parking lot capacity, service radius, management, and charges should be considered. The most appropriate type of parking lot should be selected according
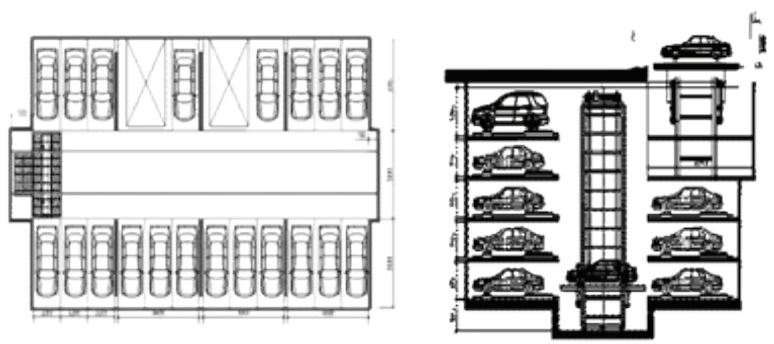

Fig. 6. Aisle-stack mechanical parking system.

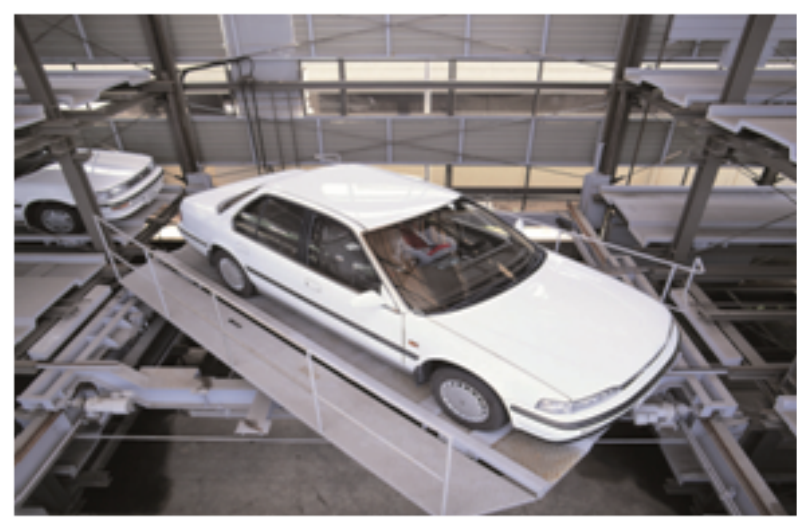

Fig. 7. Lift-sliding mechanical parking system. 
to the principles of appropriateness, reliability, and humanity. When the underground space is relatively large, an aisle-stack mechanical parking system and lift-sliding mechanical parking system can be adopted. When the underground space is deep and narrow, a vertical lifting underground mechanical parking lot can be adopted. When one direction of the underground space is long and the other side narrow, it is best to opt for a horizontal circulating mechanical parking system. Finally, when an ordinary parking lot is mechanically transformed, a mini mechanical parking system should be selected [12].

\section{Planning and design technology of urban underground parking lots}

\subsection{Underground parking planning}

An urban underground parking lot is an important node in the city. It connects the city's dynamic and static traffic and coordinates the planning and development thereof. Furthermore, it plays an important role in regulating the flow and direction of the city's traffic. Therefore, the planning of an urban parking lot should be valued so that it can play a role in promoting and guiding urban development. Based on an investigation of the construction of China's parking lots, the following recommendations are proposed for the planning of underground parking lots in China.

6.1.1 According to the demand for parking, scientifically construct and rebuild underground parking lots

In recent years, with the rapid growth in the number of motor vehicles, major cities have accelerated the pace of parking lot construction. However, new parking lots are often planned in development areas or new and high-tech development zones. Although the number of parking spaces has increased, parking difficulties in urban areas cannot be alleviated, because of low utilization rates. Therefore, the need for parking must be studied when planning and building new parking lots. The focus should be on places where gaps are prominent such as at schools, hospitals, bustling commercial areas, and residential areas. According to the specific site conditions and functional divisions, the following four situations can be delineated.

(1) Construction of core area parking lots

Key to the construction of parking lots in the core area is solving the problem of parking difficulties in areas with administrative functions and Hutong. Specific measures are as follows: transforming and expanding the parking facilities of administrative office areas using simple lifting equipment, lifting and traversing equipment, and other machinery; solving the problem of parking difficulties in Hutong by constructing simple mechanical parking lots at the corner thereof; and utilizing the surrounding public facilities and underground space of urban green areas to construct a three-dimensional underground mechanical parking lot scientifically and rationally.
As shown in Fig. 8, the parking lot of the Cheniandian Hutong adopts a sunken stereoscopic parking plan. The parking garage has a 4-story structure with 193 parking spaces.

(2) Construction of a hospital parking lot

Key to the construction of parking lots at hospitals is excavating the hospital's own space resources. For example, the surrounding public facilities and underground space in urban green areas can be used to plan and construct underground mechanical parking garages, such as a cylindrical underground parking lot.

(3) Construction of parking lots around World Cultural Heritage sites

Key to the construction of parking lots around World Cultural Heritage sites is strengthening the management of parking facilities around businesses districts and scenic spots, controlling the demand for private car parking and encouraging public transport. Combined with the bus station around World Cultural Heritage sites, a three-dimensional transformation should be implemented. Furthermore, the transformation should consider parking for tourist busses to meet the needs of tourism parking.

Fig. 9 shows the underground automatic lift parking around Beijing South Luogu Lane. The remodeled parking lot has a six-layer structure and provides 74 parking spaces. The area of the underground parking lot is nearly $2000 \mathrm{~m}^{2}$, but only about

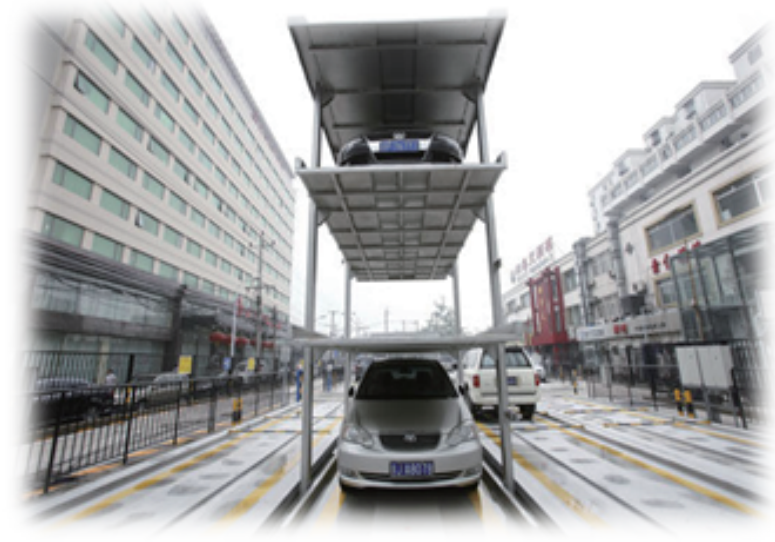

Fig. 8. Parking lot of the Cheniandian Hutong.

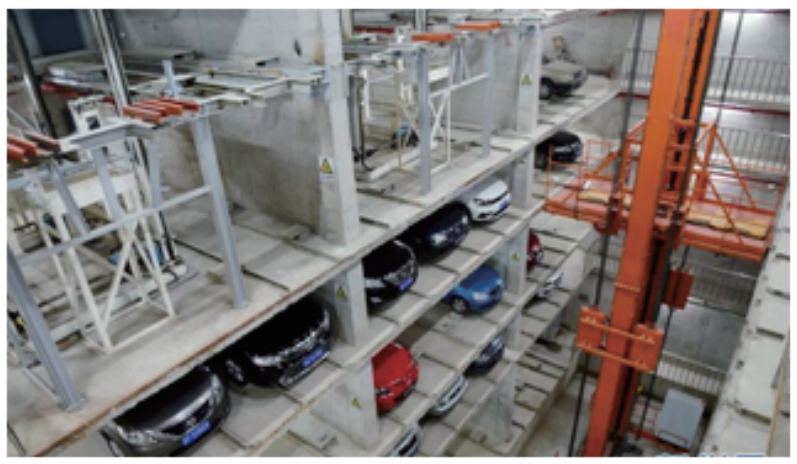

Fig. 9. Underground automatic lift parking around Beijing South Luogu Lane. 
$100 \mathrm{~m}^{2}$ can be seen on the ground; thus, the appearance of South Luogu Lane is retained.

(4) Construction of parking lots in residential areas

If parking lots in existing residential areas cannot meet the demand, mini mechanical parking systems can be constructed in public spaces or corner areas in residential areas. In addition, cylindrical underground parking lots can be constructed using the underground space of surrounding public facilities and urban green spaces.

Furthermore, at public transport hubs, transfer stations, gymnasiums, hospitals, other places of business, shopping malls with entertainment measuring more than $5000 \mathrm{~m}^{2}$, and other entertainment establishments, when the construction of the parking lot is insufficient, it should be rebuilt, expanded, or supplemented over time. In addition, an underground mechanical parking lot with high land utilization should be planned and designed.

\subsubsection{Graded planning of underground parking}

To control the amount of car traffic flowing to the central area of the city, Beagle, a German, proposed a method to grade parking facilities during the planning of parking lots and reduce the flow of traffic in the central area of the city through parking classification and transfer. Beagle divides parking facilities into three levels, arranging a large, long-term parking lot at each of the four corners of the city's central area. A large public transport interchange station is also available near the parking lot. Drivers can reach the city center using public transport. If a ring road is constructed on the periphery of the central area, drivers can park their cars in the parking lot on the inner side of the ring road after entering it from the expressway. This is an intermediate type of parking lot (both long-term parking and short-term parking) [12]. A small number of vehicles that need to enter the city center in a short time can enter through the auxiliary road of the ring road. Similarly, there is a short-term parking lot at the end of the auxiliary road. After parking, drivers can walk into the central area of the city. This layout also creates a sub-center on the left side of the city's core area, and establishes two large, long-term parking lots at the outside of the highways located at both ends of the sub-center [13]. As mentioned, this parking layout was proposed by Beagle, and is shown in Fig. 10.

To reduce the traffic flow in the urban center area and solve

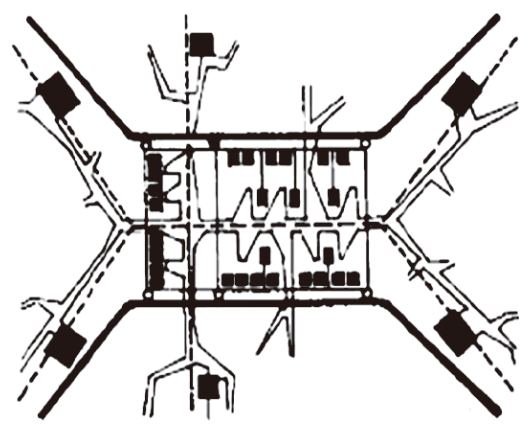

Fig. 10. The parking layout proposed by Beagle. the difficulty of parking in crowded areas, it is recommended to adopt the principle of hierarchical planning of parking lots. Furthermore, "Park-and-Ride" underground intelligent parking lots should be constructed in densely populated areas outside the city center such as public transportation hubs, fast-track entrances and exits, and central business districts. Low fees and more favorable public transport charges also need to be implemented simultaneously. Implementing the above measures promotes the development of parking and transfer and public transportation, reduces the traffic flow in urban center areas, and optimizes the structure of urban traffic organization.

\subsection{Underground parking design}

6.2.1 Structural design of underground mechanical parking lots

The design of the space of underground mechanical parking lots includes space design of the column grid, section design, and entrance and exit design [7]. The space design of the column grid should consider the spacing of the mechanical structure, size of the vehicle, and combination of structures to maximize space utilization. Section design considers the net height of the vehicle and mode of mechanical operation. As shown in Fig. 11, the basic reference size of a single parking space is $5.05 \mathrm{~m} \times 1.85 \mathrm{~m}$ $\times 1.55 \mathrm{~m}$ (length $\times$ width $\times$ height). The design of the entrance and exit of an underground mechanical parking lot incorporates lifters to increase the efficiency of accessing vehicles. Attention should be paid to coordination with the surrounding environment. The dimensions of the entrance and exit should meet the following requirements. The width should be more than $0.5 \mathrm{~m}$ greater than the maximum width of the transported vehicles and the total width should be at least $2.25 \mathrm{~m}$. The height should be more than $1.8 \mathrm{~m}$, and the total height at least $0.1 \mathrm{~m}$ more than the height of the parked vehicles [13].

The design of the super-structure and retaining structure of an underground parking lot considers the safety and reliability of the structure. Retaining structures should be selected according to the project conditions. Commonly used retaining structures include underground diaphragm walls and bored piles.

When designing anti-drainage and smoke exhaust systems, the waterproof level of underground mechanical parking lots must be determined, weak joints such as the deformation joints of construction joints reduced, and waterproofing measures im-
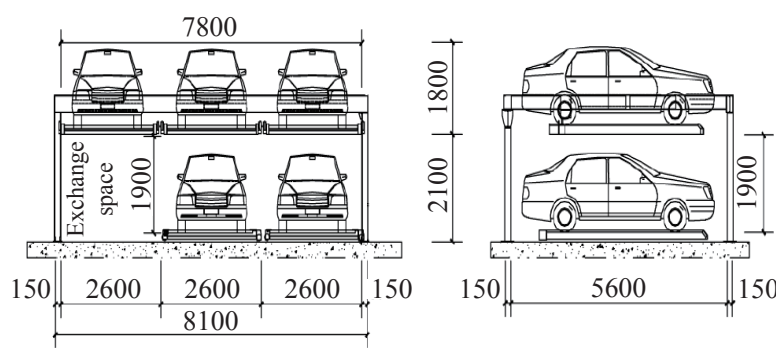

Fig. 11. Design of the space of the parking lot (unit: $\mathrm{mm}$ ). 
plemented to prevent the mechanical structure from corrosion and seepage. Furthermore, a smoke exhaust system should be installed to eliminate automobile exhaust fumes and smoke produced by fire to ensure that accidents are timeously dealt with and losses reduced.

6.2.2 Design of the auxiliary facilities of underground mechanical parking lots

Intelligent design of parking management. The design features of intelligent parking lots include the following aspects: intelligent equipment, reduced access time, intelligent operation, low thresholds for use, easy access to the vehicle, intelligent security mode, installation of multiple security settings to ensure the safety of vehicles and people, monitoring intelligence to avoid theft and other phenomena, and intelligent maintenance that includes smartly testing the operating status of equipment and reduces maintenance management. An intelligent management system integrates functions such as timing, charging, and status information $[12,13]$.

Parking exchange technology. Parking exchange technology enables vehicles to automatically enter the corresponding parking space from the track. This technology affects the speed of parking, design of the space, and reliability of the parking lot. The exchange technology of parking equipment can be delineated into two categories, namely with or without a steel structure. This structure should be selected and improved according to the project conditions.

Parking control system. The underground mechanical parking control system is an important aspect of parking lot automation including the vehicle sensing system and automatic access vehicle system. It is important in aspects such as operation, maintenance, and security. Currently, mechanical parking lots generally adopt a programmable logic controller (PLC) control system [7].

\section{Parking lot construction technology}

\subsection{Common construction methods}

Underground parking lot construction technology is essentially a deep foundation pit created through open cut, cover-cut, or open caisson methods. Table 2 outlines the specific application conditions.

Selecting a method by which to construct retaining structures is based on the characteristics of the project and geological conditions. Underground diaphragm walls are suitable for foundation pits with high deformation and waterproof requirements, and can be used as part of the main structure; however, the cost is high. The cost of bored pile is relatively low and has high rigidity, making it suitable for the construction of deep foundation pits.

\subsection{Shaft construction method}

The cylindrical underground parking lot is relevant here, because of its small footprint, wide applicable range, and high space utilization. The underground structure of this type of parking lot is similar to a shaft structure. Therefore, the following shaft construction method can also be used. (1) If the conditions of the stratum are suitable, and the site is open, an ordinary drilling and blasting method can be used to excavate the shaft. (2) If the depth of the shaft is large and the construction site conditions are appropriate, mechanical drilling can be used. This method can prefabricate the borehole wall while excavating, improve the quality of construction, and shorten the period of construction. (3) When unstable geological conditions are evident such as high moisture content and the existence of mucky soil and quicksand, the freezing method can be used, which means using artificial freezing technology to freeze the rock mass around the shaft before excavating it.

\subsection{New technologies, new methods}

With the continuous development of underground engineering, new methods or improved technologies are emerging. (1) Sphere shield construction technology. The sphere shield can complete the excavation of a vertical foundation pit and be turned in the shaft to directly excavate the underground space required for the parking lot. The advantages of this technology

Table 2. Application of different construction methods.

\begin{tabular}{ll}
\hline Construction methods & Applicable conditions \\
\hline $\begin{array}{l}\text { Unprotected open cut } \\
\text { excavation }\end{array}$ & $\begin{array}{l}\text { This method is applicable for foundation pits or trenches with relatively open field conditions, and the foundation pit is } \\
\text { located at a depth of } 50 \mathrm{~m} \text { above the groundwater level, or the stratum and base have a good self-stabilizing ability after } \\
\text { precipitation. }\end{array}$ \\
$\begin{array}{l}\text { Vertical open cut } \\
\text { This method is applicable for pits or trenches with a high density of buildings around the site and relatively narrow site } \\
\text { conditions. For example, the depth of foundation pits is large, groundwater level is high, and the stratum has almost no } \\
\text { self-stabilization ability. Furthermore, the environmental protection requirements are relatively high. }\end{array}$ \\
$\begin{array}{l}\text { This method is suitable for relatively small excavation areas. When the traffic cannot be interrupted for a long time or the } \\
\text { impact on residents' lives is too large, the cover-cut method is used. }\end{array}$ \\
This method is suitable for strata with soft soil, low friction, and low depth of subsidence. It has a small range of \\
disturbance to surrounding soil and is particularly suitable for urban areas where buildings are dense.
\end{tabular}


are its small environmental impact, high structural stability, and ability to save on workload. (2) "Pile-wall combination" technology. As shown in Fig. 12, this method combines the technology of secant piles, underground diagram walls, and open caisson, and integrates the retaining and waterproofing functions of the enclosure structure to form a "three-in-one wall" structure. This new technology is significant in saving energy and reducing consumption, and contributes to the sustainable development of foundation pit supports. As such, it can be well utilized in the construction of underground parking lots.

\section{Conclusions}

(1) In the process of developing urban underground parking lots, efficiency, safety precautions, and the management of existing parking lots should be improved

Through the coordination of urban dynamic and static traffic, rational guidance of regional traffic flow, and improvement of urban planning, the utilization rate of existing parking lots will be increased. By using the Internet, Internet of Things, and other technologies, an intelligent parking management system can be developed. Through intelligent booking, intelligent parking guidance, intelligent identification, and other functions, the intensive management and security of parking lots can be improved. According to information obtained from big data such as regional parking demand and urban traffic development, the layout of cities will be optimized and city development promoted scientifically, efficiently, and healthily.

(2) Flexible handling of construction management and investment and financing modes

The construction and management of parking lots are based on the diversification of construction, management of localization, and intelligentization of facilities, and achieved through co-ordination, integration, and intensiveness. We must use various means including legal, administrative, technological, and financial aspects, and adhere to the combination of government guidance and market leadership.

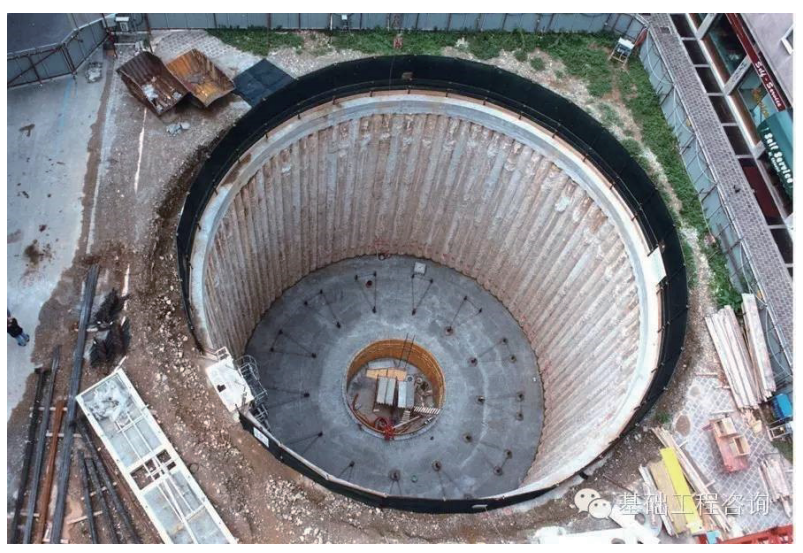

Fig. 12. "Pile-wall combination" cylindrical structure.
(3) According to needs related to parking, underground parking lots should be planned and designed based on local conditions

Planning for underground parking lots should consider space characteristics and urban layout. Currently, underground mechanical parking lots provide many advantages such as a small footprint, flexible structure, high degree of automation, safety, and reliability, which should be prioritized in the construction or renovation of urban parking lots.

(4) When developing urban underground parking lots, suitable construction methods can promote the development of the parking industry

Construction methods such as open-cutting and undercutting should be selected according to the engineering environment. Furthermore, rapid construction and prefabricated structural assembly construction technologies should be developed, and the supporting facilities, mechanical structures, and control systems of underground parking lots unified. Ultimately, a complete industrial chain will be formed, the efficiency of parking lot construction increased, and the industrialization of parking lots and development of the urban economy promoted.

\section{References}

[1] Wang M S, Wang Y H, Tan Z S, et al. Exploration on the comprehensive utilization of underground space in China's smart city [J] Journal of Beijing Jiaotong University, 2016, 40(4): 1-8. Chinese.

[2] Qi J. Tintin parking: To create a static traffic ecosystem [J]. Transport Business China, 2015 (21): 66-69. Chinese.

[3] Bie M. Study on the prediction of parking demands and parking management strategy of Chongqing New Northern Zone (Master's thesis) [D]. Chongqing: Chongqing Jiaotong University, 2011. Chinese.

[4] Gong J G, Zhu J A. Research on the governance countermeasure for illegal on-Street parking in urban road [J]. Auto \& Safety, 2015 (12): 104-107. Chinese.

[5] http://www.ndrc.gov.cn/zclb/zcfbtz/201s08/t201s0811_ 744943. htm1.National Development and Reform Commission of the PRC. Guiding opinions on strengthening the construction of urban parking facilities [EB/OL]. (201s-08-03) [2017-09-12]. http://www. ndrc.gov.cn/zcfb/zcfbtz/201 s08/t20150811_ 744943.htm1. Chi nese.

[6] Dong S H, Zhang C H. Study on parking problems in some countries and regions [J]. Urban Planning Overseas, 1999 (4): 37-41. Chinese.

[7] Wang H. The research and application (Master's thesis) [D]. Changsha: Hunan of solid machinery garage University, 2008. Chinese.

[8] Yu S J, Yin B C, Liu Z P Study on the development of static traffic at home and abroad [J]. City, 2011 (9): 89-91. Chinese.

[9] Guan H Z, Ren J, Yao S Y. The urban parking policy at the early and middle period of motorization in the developed countries $[\mathrm{J}]$ City Planning Review, 2002, 26(10): 81-84. Chinese.

[10] Zhu D Q. Problems and solutions of static traffic management in 
medium-sized city take Jinhua as an example (Master's thesis) [D] Hangzhou: Zhejiang Normal University, 2009. Chinese.

[11] Wen Q Y, Lu L Q. A Review of the present situation and development of stereo garage at home and abroad [J]. Logistics Engineering and Management, 2016, 38(7): 159-161. Chinese.
[12] Shen L H. Stereoscopic parking planning-Discuss intensive land use mode of parking planning [J]. Traffic \& Transportation, 2016(z2): 112-116. Chinese.

[13] Zhang X Y. Urban parking planning and management [M] B e i jing: China Architecture \& Building Press, 2006. Chinese. 